\title{
COMPARISON OF TWO METHODS OF FIXATION OF SUPRACONDYLAR FRACTURES OF THE HUMERUS IN CHILDREN
} COMPARAÇÃO DE DOIS MÉTODOS DE FIXAÇÃO DE FRATURAS
SUPRACONDILIANAS DO ÚMERO EM CRIANÇAS

\author{
Henrique Melo natalin ${ }^{1}$ (i), Jéssica Colamarino Sessa da Silva ${ }^{2}$ (i), José Batista Volpon ${ }^{1}$ (1)
}

1. Universidade de São Paulo, Ribeirão Preto Medical School Teaching Hospital, Ribeirão Preto, SP, Brazil.

2. Universidade de São Paulo, Ribeirão Preto Medical School, Ribeirão Preto, SP, Brazil.

\section{ABSTRACT}

Objective: To compare the outcomes of the fixation of complete and displaced supracondylar humeral fractures in children with two different Kirschner wire configurations. Methods: The type of fixation was randomized to either crossed (19 cases), or two divergent lateral Kirschner wires (24 cases). The comparison was made six months later between the two treated groups and each group with the non-fractured elbow (clinical alignment, range of motion, Baumann angle, and lateral humeral capitellar angle). Results: 43 children were evaluated (65\% boys) with a mean age of six years and five months. The carrying angle $(p=0.94)$, extension $(p=0.89)$, and the Flynn's criteria $(p=0.56)$ were similar between the groups. The flexion was slightly smaller for the crossed wire group ( $p=0.04$ ), but similar to the uninjured side. The Baumann angle was not different between the two fixations $(p=0.79)$ and the contralateral side $(p=0.1)$. The lateral humeral capitellar angle was slightly greater for the lateral pinning $(p=0.08)$, but with no difference with the uninjured elbow $(p=0.62)$. No iatrogenic injuries were observed. Conclusion: Both fixations presented similar outcomes that did not significantly affect the carrying angle in relation to the non-fractured side. Level of evidence II, Therapeutic study - Investigating the results of treatment.

Keywords: Humeral Fractures. Bone Wires. Children.

\section{RESUMO}

Objetivo: Comparar os resultados da fixação das fraturas supracondilianas completas e desviadas do úmero de crianças com dois tipos de configuração de fios de Kirschner. Método: O tipo de fixação foi aleatorizado para fixação com dois fios de Kirchner cruzados ou laterais divergentes. Depois de seis meses foi feita a comparação entre os dois grupos fixados entre si e cada um deles com o lado não fraturado do mesmo paciente (alinhamento clínico, arco de movimento, critérios de Flynn, ângulos de Baumann e capituloumeral). Resultados: Participaram do estudo 43 crianças (65\% meninos), com idade média de seis anos e cinco meses. A extensão ( $p=0,89)$, o ângulo de carregamento $(p=0,94)$ e os critérios de Flynn $(p=0,56)$ foram semelhantes entre os dois grupos, sem ocorrência de lesões iatrogênicas. A flexão foi discretamente menor no grupo com fios cruzados $(p=0,04)$, mas próximo do cotovelo normal. O ângulo de Baumann não apresentou diferença entre as duas fixações $(p=0,79)$, bem como com o lado não fraturado $(p=0,01)$. O ângulo capituloumeral foi ligeiramente maior $(p=0,08)$ nos fios laterais, mas sem diferença em relação lado normal $(p=0,62)$. Conclusão: As duas fixações apresentaram resultados similares e não alteraram significativamente o ângulo frontal do cotovelo em relação ao lado não fraturado. Nível de evidência II, Estudo terapêutico - Investigação dos resultados do tratamento.

Descritores: Fraturas do Úmero. Fios Ortopédicos. Crianças.

Citation: Natalin HM, Silva JCS, Volpon JB. Comparison of two methods of fixation of supracondylar fractures of the humerus in children. Acta Ortop Bras. [online]. 2021;29(5):263-267. Available from URL: http://www.scielo.br/aob.

\section{INTRODUCTION}

Supracondylar humeral fractures, the most common in the immature elbow, ${ }^{1}$ when displaced, should be reduced and fixed by means of the percutaneous technique with two or three Kirschner wires, as they present intrinsic instability. The wires can be inserted in crossed configuration, one into each epicondyle, or all of them (two or three) through the lateral epicondyle. When crossed, fixation is mechanically more stable, but there is a higher risk of injury to the ulnar nerve. ${ }^{2}$
Among North American orthopedists, 30\% prefer crossed wires, $33 \%$ prefer insertion of two lateral wires, and $37 \%$ prefer the use of three lateral wires. ${ }^{3}$ Therefore, the options are quite balanced and wire configuration seems to be a surgeon's personal choice.

The Gartland classification ${ }^{1}$ has been reviewed and includes the types in flexion and those in extension I, II, III or IV, ${ }^{4}$ depending on the degree of affection of the fracture and characteristic of the displacement. There are several publications on treatment types, but most of them refer to retrospective series. A meta-analysis recommends lateral wires

All authors declare no potential conflict of interest related to this article. 
for type II fractures and crossed wires for types III or IV fractures, with mini access technique for medial wire, ${ }^{5}$ while another recommends the use of laterally inserted wires. ${ }^{6}$ Finally, a third concluded that there is not enough evidence to recommend one or another configuration, but that, if the surgeon wants to avoid the potential risks of iatrogenic injury to the ulnar nerve, the lateral insertion of wires is safer. ${ }^{7}$

Based on these assumptions, we conducted a random and prospective study whose objective was to analyze the outcomes of the treatment of displaced supracondylar humeral fracture and fixed with two Kirschner wires inserted crosswise (through the lateral and medial condyles) or only through the lateral condyle.

\section{MATERIALS AND METHODS}

The project was approved by the Institution's Ethics Committee (CAAE): 02703418.8.0000.5440). The individuals included were treated at an emergency unit of the Unified Health System between June 2015 and December 2018. The inclusions were: complete and displaced supracondylar humeral fractures (Gartland type III ${ }^{1}$ ) (Figure 1) in children of any age. The legal guardians authorized the inclusion in the study and committed to adhere to the postoperative follow-up for at least six months. Exclusion criteria were other associated fractures, head trauma, Gartland I and II fractures, ${ }^{1}$ bilateral, exposed fractures, need for open reduction, presence of previous trauma sequelae on any of the elbows, fixation with more than two metallic wires in the same epicondyle, and loss of follow-up.
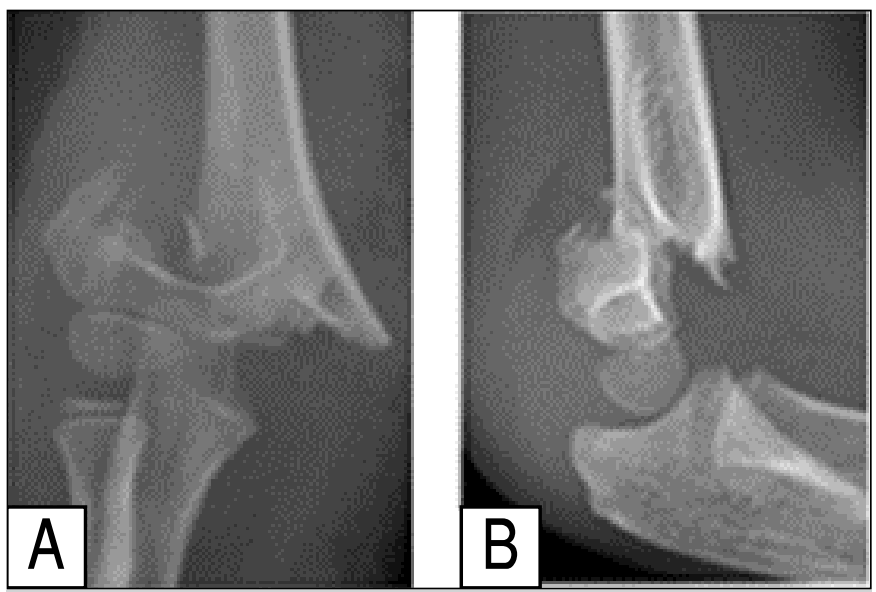

Figure 1. Illustration of a typical fracture classified as Gartland type III. The fracture is complete, displaced in more than one plane and unstable.

Initial care involved careful evaluation of limb circulatory conditions and possible neurological injuries. The randomization of the type of fixation (crossed or just lateral wires) was performed through the website random.org (https://www.random.org/).

According to the flow chart in Figure 2, there were 734 cases of orthopedic pediatric trauma during the study period, with 107 supracondylar fractures (14.5\%). Of these, 61 were completely displaced and classified as Gartland III (1) (57\%) and randomized for treatment with two crossed Kirschner wires, or two divergent lateral wires. There was exclusion of two patients that underwent open reduction and three who did not attend follow-up for a minimum of six months. The final sample consisted of 43 cases, of which 24 cases with fixation with lateral wires (56\%) and 19 cases with fixation with crossed wires (44\%).

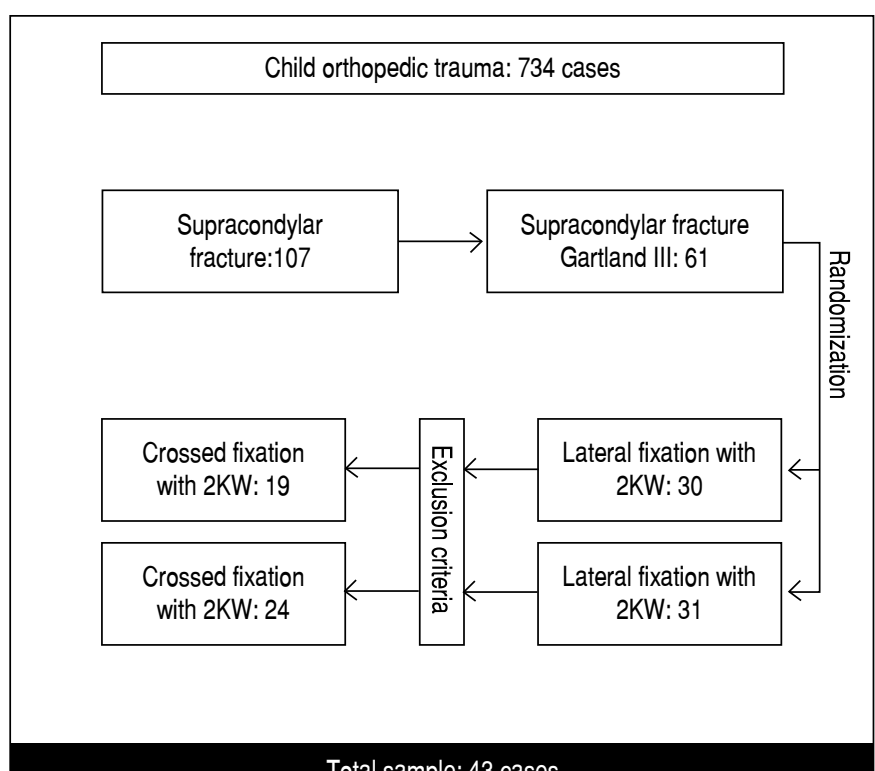

Total sample: 43 cases

Figure 2. Patient selection flow chart. KW: Kirschner wire; Gartland III: complete and displaced fractures.

\section{Fracture reduction and fixation technique}

Fracture reduction was performed under general anesthesia, with the child in the supine position and the fractured upper limb resting on an auxiliary table for the hand. After routine antisepsis procedures, the following steps were performed under the control of the image intensifier: traction with the elbow in semiflexion, correction of the lateral or medial displacement, and correction of the posterior displacement with support on the olecranon, associated with elbow flexion. After confirmation of the adequacy of the reduction (displacements corrected and alignment of the medial and lateral elbow columns). In cases with only lateral fixation, flexion was maintained, the lateral epicondyle was identified, and two $2.0 \mathrm{~mm}$ thick Kirschner wires directed towards the lateral elbow column were introduced in a divergent manner until they reached the opposite cortex (Figure 3A). For the crossed wires, the wire through the lateral epicondyle was inserted first, as already described. Then, the elbow was partially extended, the epicondyle was palpated, and a small surgical access was made to identify the ulnar nerve. Then, the Kirschner wire was introduced towards the medial column, until reaching the opposite cortex (Figure 3B).
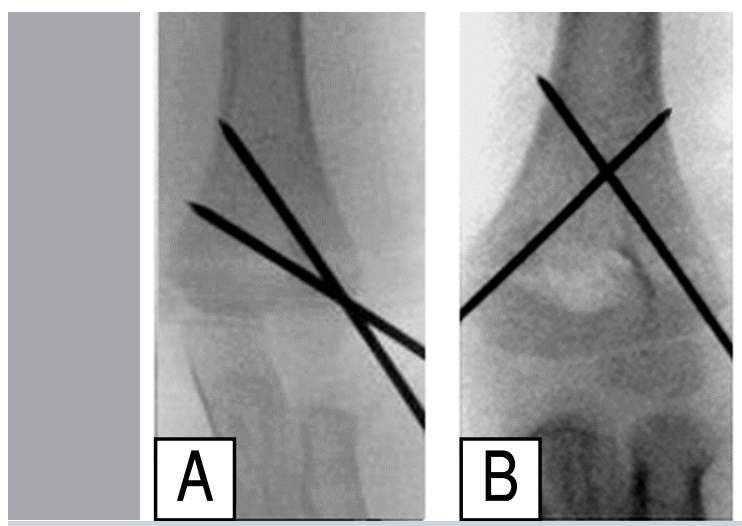

Figure 3. Illustration of the two types of fixation evaluated. A: Two divergent lateral Kirschner wires inserted through the lateral epicondyle; B: Two Kirschner wires crossed above the fracture inserted through the epicondyles. 
The exit end of the pins was left out of the skin and folded to be removed after X-ray in three weeks. Still in the surgical environment, after final confirmation of the reduction and fixation (front, side, and oblique incidence to visualize the positioning of the wires, the two columns, as well as stability test with arm rotation), an axillopalmar splint cast was applied with the elbow held at $90^{\circ}$ angle of flexion and neutral rotation of the forearm. The first evaluation was performed after one week, then in three weeks for removal of Kirschner wires (after radiography without the splint), and in the fourth week to remove the immobilization and guide home physiotherapy. There was a new evaluation after one month and, finally, in six months. Intermediate evaluations were performed in cases of nerve injury due to fracture or difficulty in gaining movement. In the last evaluation, we measured the frontal alignment and the range of motion of both elbows and applied the Flynn criteria, ${ }^{8}$ as described in Table 1.

\begin{tabular}{c|c|c|c}
\multicolumn{2}{c}{ Chart 1. Flynn clinical criteria ${ }^{8}$ for evaluating the outcome of treatment. } \\
\hline Outcome & Result & $\begin{array}{c}\text { Cosmetic Factor } \\
\text { (Loss of carrying } \\
\text { angle, in degrees) }\end{array}$ & $\begin{array}{c}\text { Functional Factor } \\
\text { (Loss of range of } \\
\text { motion, in degrees) }\end{array}$ \\
\hline Satisfactory & Excellent & $0-4.9$ & $0-4.9$ \\
\hline & Good & $5-9.9$ & $5-9.9$ \\
\hline & Fair & $10-14.9$ & $10-14.9$ \\
\hline unsatisfactory & Poor & $\geq 15$ & $\geq 15$ \\
\hline
\end{tabular}

In the final evaluation, both elbows were radiographed to obtain the Baumann angles $\left(64^{\circ} \text { to } 81^{\circ}\right)^{9}$ and the humeral capitellar angle $\left(45^{\circ}\right.$ to $\left.57^{\circ}\right),,^{10}$ as illustrated in Figure 4.

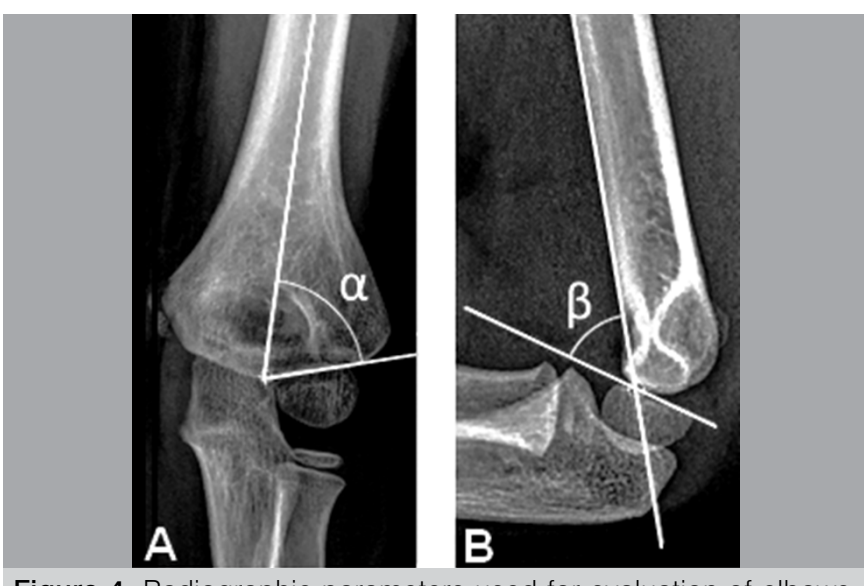

Figure 4. Radiographic parameters used for evaluation of elbows. A: The Baumann angle is formed by the intersection between the longitudinal line of the humerus and a line tangential to the growth plate of the capitellum; B: The humeral capitellar angle is formed by a line tangential to the anterior surface of the humerus and another line tangential to the growth plate of the capitellum.

\section{Grouping}

Two groups were formed: 1) Fixation with two crossed Kirschner wires; 2) Fixation with two lateral Kirschner wires. As in each group the fractured side was compared with the respective normal side, there were two subgroups (crossed wireds $x$ normal side and lateral wires $x$ normal side).

\section{Statistical analysis}

Comparisons were made between the two fixed groups with each other and, in each treated group, with the other non-fractured elbow (statistical significance was $\leq 0.05$ ). In the normal distribution (Shapiro-Wilk test), we used comparisons of numerical variables, ANOVA and the $t$ test for independent samples and paired samples. In the nonparametric distribution, we used the Mann-Whitney test and Spearman's correlation. The chi-square $\left(\chi^{2}\right)$ test was used for categorical variables. The program SPSS v.22.0 (IBM Statistical Package for Social Sciences, United States) was employed.

\section{RESULTS}

We evaluated 43 patients, 28 boys (65\%) with mean age of six years and five months and 15 girls (35\%) with mean age of five years and seven months. All fractures were of the extension type, 28 of them (65\%) with posteromedial displacement and 15 (35\%) with posterolateral displacement. There was no significant difference between the groups regarding age $(p=0.45)$, sex $(p=0.33)$ and initial fragment displacement $(p=0.62)$.

In 24 cases, fixation was performed with lateral wires (56\%), and in 19 cases with crossed wires (44\%). Four patients had nerve injury in the first instance of service (one ulnar nerve, two median nerves and two radial nerves), which regressed completely and spontaneously. There was no compartment syndrome, vascular injury, treatment-related nerve injury, or pin infection.

Flexion was slightly smaller in the group fixed with crossed wires, compared with the group fixed with lateral wires $(p=0.04)$, but close to the subgroups ( $p=0.12$ ). There was no difference in extension capacity when comparing patients treated with lateral and crossed wires $(p=0.10)$, or with the unfractured side $(p=0.89)$. The recovery of extension occurred on average eight weeks after the removal of immobilization. The carrying angle was similar in the comparison between the fractured and the unfractured side, in both types of fixation ( $p=0.94$ ).

The Baumann angle was not significantly different between the two types of fixation $(p=0.79)$. When the comparison was made in relation to the non-fractured side, the two types of fixation presented slightly larger numbers $(p=0.01)$, which shows a slight residual deviation in varus. The humeral capitellar angle was slightly greater in patients treated with lateral wires $(p=0.08)$ in relation to crossed wires, but there was no significant difference compared to unfractured elbows ( $p=0.62$ )

The results, according to Flynn criteria, are shown in Figure 5, with no significant difference between the two treatment methods when compared with each other, or with the unfractured sides $(p=0.56)$.

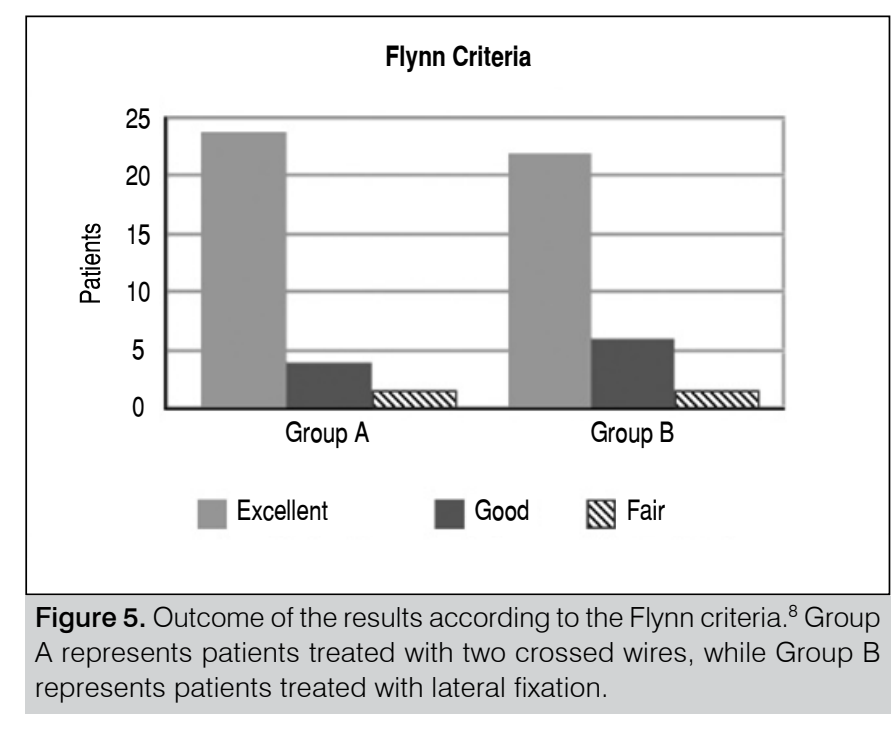




\section{DISCUSSION}

Supracondylar fracture of the humerus in children is a commonly studied condition in pediatric orthopedic traumatology. However, several existing publications have a retrospective design and some biases. Our study was randomized and prospective, in addition to using the unfractured elbow for comparison.

The fracture under study results from the weakening of the supracondylar region of the humerus, because in children the cartilaginous component at the end of the elbow is large, associated with the fact that there is overlap of the olecranon and coronoid fossae. The end of the humerus is supported by two bone columns, which are more fragile in the growing bone. Supracondylar fracture occurs more frequently in children with greater ligament looseness, especially in those with physiological antecurvature of the elbow. This causes the elbow to have forced hyperextension when one falls with support on the flat hand, favoring posterior displacement. The same trauma in children without increased ligament looseness tends to cause fracture of the distal end of the forearm. ${ }^{11}$

This fracture is one of those with the greatest potential for acute (neurovascular) or late (vicious consolidation) complications. In addition, unlike what occurs in other fractures of the immature skeleton, it has a small capacity for remodeling. ${ }^{12}$ Therefore, the definitive reduction should be anatomical and the fixation maintained until the formation of a stable bone callus, which occurs between three and four weeks. ${ }^{13}$

Some therapeutic approaches are already well established for these fractures, such as the need for proper reduction and fixation, because they are potentially unstable, since the distal fragment is relatively small, the elbow joint is close and the fracture occurs in a flattened region of the bone, which causes that there is little contact area between the fragments. The most frequent vicious consolidation is in varus and may occur due to insufficient initial reduction, or loss of the reduction obtained. The latter possibility is controlled by proper fixation. Classically, vicious consolidation in varus was seen as a purely aesthetic problem. However, it was observed that this deviation in the adult population may cause rotatory instability, ${ }^{14}$ late ulnar neuropathy, ${ }_{15}^{15}$ snapping triceps syndrome ${ }^{16}$ or progressive varus in the ulna. ${ }^{17}$

Even if only deformity is considered, it is in a habitually exposed region, there is a compromise of self-image, which can lead to loss of self-esteem and psychological difficulties.

Our analysis shows that both fixation configurations studied here presented good results and that, using the purely clinical parameters, there was no difference between the two techniques, and there was no significant difference between the fractured elbow and the contralateral elbow. This is especially important because when extending the elbows it is intuitive to compare the alignment between them. The radiographic parameters of the fractured and control groups showed that Baumann angle was statistically similar in the elbows fixed with lateral and crossed wires; however, it was smaller compared to the unfractured side, which means slight residual deviation in varus. The comparison of these angles with the normal elbow is very important because their physiological variations are large. On the other hand, the comparison of the humeral capitellar angle showed that the elbows treated with lateral wires showed a slight anterior deviation in relation to the crossed wires.

In our series there was no iatrogenic lesion of the ulnar nerve, a care that should be reinforced since between $5.7 \%$ and $17.7 \%$ of children may present anterior subluxation of this nerve, with elbow flexion, ${ }^{18}$ which favors a possible migration of the nerve and injury in the introduction of the medial wire. Since, from a technical point of view, fixation with only lateral wires is simpler and with less risk of nerve injury, it may be preferred for common fractures. Since crossed wires provide more stability, ${ }^{5}$ they could be reserved for the most unstable fractures, such as those with medial comminution, or with multidirectional instability that results from the rupture of the entire periosteal wrap, but these particularities were not investigated in our study. In addition, in our methodology, we did not compare the images of the immediate surgical reduction with those after the fracture consolidation, which does not allow the assessment of a possible loss of reduction.

As limiting factors in our investigation, we highlight the relatively small number of cases, although this was compensated by the prospective methodology, by the randomization and homogeneity of the sample. In addition, we did not evaluate the possibility of reduction loss and rotational deviation, which is of little importance in terms of function, but may compromise the stability of fixation. By decreasing the contact between the fragments and making it difficult to locate the wires properly.

In summary, our analysis shows that the two types of fixation of the supracondylar humeral fracture present similar clinical outcomes. One difference is that with crossed wires there was smaller extension, but the evolution of this finding would require longer follow-up time. Because fixation with crossed wires is technically more difficult and potentially more dangerous for ulnar nerve injury, it could be left as a secondary choice for fractures that are more severe, unstable and with significant displacement, which means major periosteal injury. ${ }^{5}$

\section{CONCLUSION}

Both types of supracondylar fracture fixation presented similar clinical outcomes and there was no significant change in the frontal alignment of the elbow or function compared to the unfractured side.

AUTHORS' CONTRIBUTION: Each author contributed individually and significantly to the development of this article. HMN: acquisition, analysis and interpretation of data, writing; SCSS: aid in the acquisition and analysis of data; JBV: conception and design of the study, critical review of its intellectual content and final approval of the manuscript.

\section{REFERENCES}

1. Gartland JJ. Management of supracondylar fractures of the humerus in children. Surg Gynecol Obstet. 1959;109(1):145-54.

2. Brauer CA, Lee BM, Bae DS, Waters PM, Kocher MS. A systematic review of medial and lateral entry pinning versus lateral entry pinning for supracondylar fractures of the humerus. J Pediatr Orthop. 2007;27(2):181-6.

3. Carter CT, Bertrand SL, Cearley DM. Management of pediatric type III supracondylar humerus fractures in the United States: results of a national survey of pediatric orthopaedic surgeons. J Pediatr Orthop. 2013;33(7):750-4

4. Leitch KK, Kay RM, Femino JD, Tolo VT, SK Storer, DL Skaggs. Treatment of multidirectionally unstable supracondylar humeral fractures in children. A modified Gartland type-IV fracture. J Bone Joint Surg Am. 2006;88(5):980-5.

5. Patriota GSQA, Assunção Filho CA, Assunção CA. Qual a melhor técnica para fixação no tratamento de fratura supracondilar do úmero em crianças? Rev Bras Ortop. 2017;52(4):428-34.

6. Vaquero-Picado A, González-Morán G, Moraleda L. Management of supracondylar fracture of the humerus in children. EFORT Open Rev. 2018;3(10):526-40.

7. Dekker AE, Krijnen P, Schipper IB. Results of crossed versus lateral entry K-wire fixation of displaced pediatric supracondylar humeral fractures: A systematic review and meta-analysis. Injury. 2016;47(11):2391-8.

8. Flynn JC, Matthews JG, Benoit RL. Blind pinning of displaced supracondylar fractures of the humerus in children. Sixteen years' experience with long-term follow-up. J Bone Joint Surg Am. 1974;56(2):263-72.

9. Williamson DM, Coates CJ, Miller RK, Cole WG. Normal characteristics of the Baumann (humerocapitellar) angle: an aid in assessment of supracondylar fractures. J Pediatr Orthop. 1992;12(5):636-9. 
10. Shank CF, Wiater BP, Pace JL, Jinguji TM, Schmale GA, Bittner RC, et al. The Lateral Capitellohumeral Angle in Normal Children: Mean, Variation, and Reliability in Comparison to Baumann's Angle. J Pediatr Orthop. 2011;31(3):266-71.

11. Nork SE, Hennrikus WL, Loncarich DP, Gillingham BL, Lapinsky AS. Relationship between ligamentous laxity and the site of upper extremity fractures in children: extension supracondylar fracture versus distal forearm fracture. J Pediatr Orthop B. 1999;8(2):90-2.

12. Wilkins KE. Principles of fracture remodeling in children. Injury. 2005;36(1):3-11.

13. Einhorn TA, Gerstenfeld LC. Fracture healing: mechanisms and interventions. Nat Rev Rheumatol. 2015;11(1):45-54.

14. O'Driscoll SW, Spinner RJ, McKee MD, Kibler WB, Hasting H 2nd, Morrey BF, et al. Tardy posterolateral rotatory instability of the elbow due to cubitus varus. J Bone Joint Surg Am. 2001;83(9):1358-69.
15. Fujioka H, Nakabayashi Y, Hirata S, Go G, Nishi S, Mizuno K. Analysis of tardy ulnar nerve palsy associated with cubitus varus deformity after a supracondylar fracture of the humerus: a report of four cases. J Orthop Trauma. 1995;9(5):435-40.

16. Spinner RJ, O'Driscoll SW, Davis JR, Goldner RD. Cubitus varus associated with dislocation of both the medial portion of the triceps and the ulnar nerve. J Hand Surg Am. 1999;24(4):718-26.

17. Cha SM, Shin HD, Ahn JS. Relationship of cubitus varus and ulnar varus deformity in supracondylar humeral fractures according to the age at injury. J Shoulder Elbow Surg. 2016;25(2):289-96.

18. Zaltz I, Waters PM, Kasser JR. Ulnar nerve instability in children. J Pediatr Orthop. 1996;16(5):567-9. 